\title{
Rhizoctonia Web Blight-A New Disease on Mint in Israel
}

Nadav Nitzan, David Chaimovitsh, and Rachel Davidovitch-Rekanati, Division of Aromatic Herbs and Medicinal Plants, Agriculture Research Organization, Newe Ya'ar Research Center, Ramat Yishai 30095, Israel; Michal Sharon, Department of Plant Pathology and Weed Science, Agriculture Research Organization, Beit-Dagan 50250, Israel; and Nativ Dudai, Division of Aromatic Herbs and Medicinal Plants, Agriculture Research Organization, Newe Ya'ar Research Center

\begin{abstract}
Nitzan, N., Chaimovitsh, D., Davidovitch-Rekanati, R., Sharon, M., and Dudai, N. 2012. Rhizoctonia web blight-A new disease on mint in Israel. Plant Dis. 96:370-378.

Mentha longifolia is produced in and exported from Israel with annual revenue of US\$16 million. In 2010, a severe epidemic of unknown etiology reduced growers' returns up to $50 \%$. Disease symptoms included water-soaked lesions, necrosis, and web-like mycelia on plants. Two isolates (JV-1 and BS-1) from randomly selected symptomatic plants were identified as members of Rhizoctonia solani anastomosis groups 1-IB and 4HG-I, respectively. The fitness of JV-1 and BS-1 interacted with temperatures between 17 and $35^{\circ} \mathrm{C}$ : JV-1 grew faster and was more aggressive $(P<0.05)$ at lower temperatures $\left(<24^{\circ} \mathrm{C}\right)$,

$\left(>30^{\circ} \mathrm{C}\right)$, and the two isolates performed similarly at intermediate temperatures. Disease developed fastest at 24 to $28^{\circ} \mathrm{C}$. Yield was reduced between 46 and $100 \%$. In all, $77.5 \%$ fewer plants recovered from disease developing at 24 to $28^{\circ} \mathrm{C}$ than at 17 to 23 or 30 to $35^{\circ} \mathrm{C}$. The relationship of disease to relative humidity $(\mathrm{RH})$ fit a quadratic model $(P<$ $\left.0.0015, R^{2}=0.98\right)$. Disease was most severe at $100 \% \mathrm{RH}$, decreasing by 1.3-, 1.9-, 3-, 4.5-, and 10.5-fold with the reduction of RH from $100 \%$ to $88,76,69,55$, or $49 \%$, respectively. This is the first report of Rhizoctonia web blight in mint in Israel.
\end{abstract} BS-1 grew faster and was more aggressive at higher temperatures
Mentha is a genus of aromatic plants in the family Lamiaceae $(2,36)$. Species in this genus are almost exclusively perennial. The plant may reproduce sexually to produce true seed. However, the major means of reproduction is vegetative via rhizomes $(2,36)$. The genus is distributed across Asia, Africa, Australia, Europe, and North America (30). It tolerates a wide range of growing environments but develops optimally under cool, moist conditions with partial sunlight. Mint is grown for culinary use as a fresh or dry herb, or for its essential oil $(20,21)$. It also is used in cosmetics and as a medicinal herb; for example, in infusions as a home remedy $(30,26)$.

The leading Mentha sp. commercially cultivated in Israel is a variety of Mentha longifolia L. that is locally named "Spanish mint". The commercially cultivated Spanish mint area is approximately 75 ha. In the 2009-10 season, Israel exported 11,000 metric tons $(\mathrm{t})$ of fresh herbs to the European Union, Great Britain, and Russia, with revenue of approximately US\$112 million. Spanish mint accounted for $1,500 \mathrm{t}(12.5 \%)$ of the total fresh herbs exported, with revenue of US\$16.5 million. This is approximately $15 \%$ of the total yearly revenue from fresh herbs exported, placing fresh Spanish mint as a minor specialty crop that provides significant profits to the Israeli fresh herb grower (Mrs. Anna Meller, Association of Herb Growers of Israel, personal communication).

Spanish mint is cultivated in different areas in Israel. However, the major mint-growing areas are located in the northern region of the country and are the Jezreel and the Beit She'an (Valley of Springs) valleys. These growing areas are hot during the summer and relatively warm during the winter, with temperatures of 12 to 28 and 16 to $37^{\circ} \mathrm{C}$ for the Jezreel and Beit She'an valleys, respectively (Israeli Meteorological Service, www.ims.gov.il).

Corresponding author: N. Dudai, E-mail: nativdud@gmail.com

* The $\boldsymbol{e}$-Xtra logo stands for "electronic extra" and indicates that Figure 1 appears in color in the online edition.

Accepted for publication 6 October 2011.

http://dx.doi.org/10.1094/PDIS-04-11-0271

(c) 2012 The American Phytopathological Society
Commercially, Spanish mint is cultivated and cropped for up to 4 years. During that period of time, the foliage is harvested manually five times each year. Commercial operations cultivate mint mainly in greenhouses or tunnels, directly on the ground, or in expanded polystyrene boxes filled with tuff (volcanic coarse ash; Fig. 1A and B). The polystyrene boxes vary in size, but commonly are $130 \mathrm{~cm}$ long by $70 \mathrm{~cm}$ wide by $20 \mathrm{~cm}$ deep. The greenhouses, tunnels, or shadehouses usually are covered by polyethylene sheets or shade nets year-round (Fig. 1C). Irrigation in these facilities may be carried out with overhead sprinklers; however, aboveground drip irrigation predominates. Under these conditions, relative humidity $(\mathrm{RH})$ is very high, and free water is common at the soil level and on the lower leaves. Because the crop is aimed for the fresh market, application of insecticides or fungicides is undesirable and highly restricted.

Rhizoctonia solani J.G. Kühn (teleomorph Thanatephorus cucumerisis (A.B. Frank) Donk) is a destructive cosmopolitan, multihost, soilborne pathogen, causing a variety of symptoms on host plants such as pre- and post-emergence damping-off, root rot, foot rot, sore shin, fruit rot, and foliar and web blights (33). The species is divided into 13 anastomosis groups (AGs) characterized as AG 1 through AG $13(4,28,29,32,33)$. The AGs were previously recorded to vary in morphology, physiology, host range, biochemical and molecular characteristics, and virulence $(1,6,9,10,24)$.

In summer 2007, commercially produced Spanish mint plants in Israel were recorded rotting and the phenomenon was at first attributed to excessive irrigation. Though irrigation frequency was reduced, the phenomenon persisted and also was observed during the warm winters of 2008 through 2010. In summer (June to September) 2010 , a severe outbreak was recorded, damaging two of the five harvests that year and reducing grower revenues up to $50 \%$. In the open field as well as in the greenhouses and tunnels, immediately following harvest, brown patches of dead foliage were observed covering 30 to $50 \%$ of the cultivated area (Fig. 1C). Disease symptoms included water-soaked lesions on foliage followed by necrosis on leaves, rot of stems and stolons, and brown lesions on stolons (Fig. 1D-F). Most importantly, the symptoms were almost exclusively associated with web-like mycelia that covered the infected tissues (Fig. 1E and G). The symptoms were observed in sprinkler-irrigated as well as drip-irrigated operations and on soil or tuff, and were usually associated with wetness or free water at 

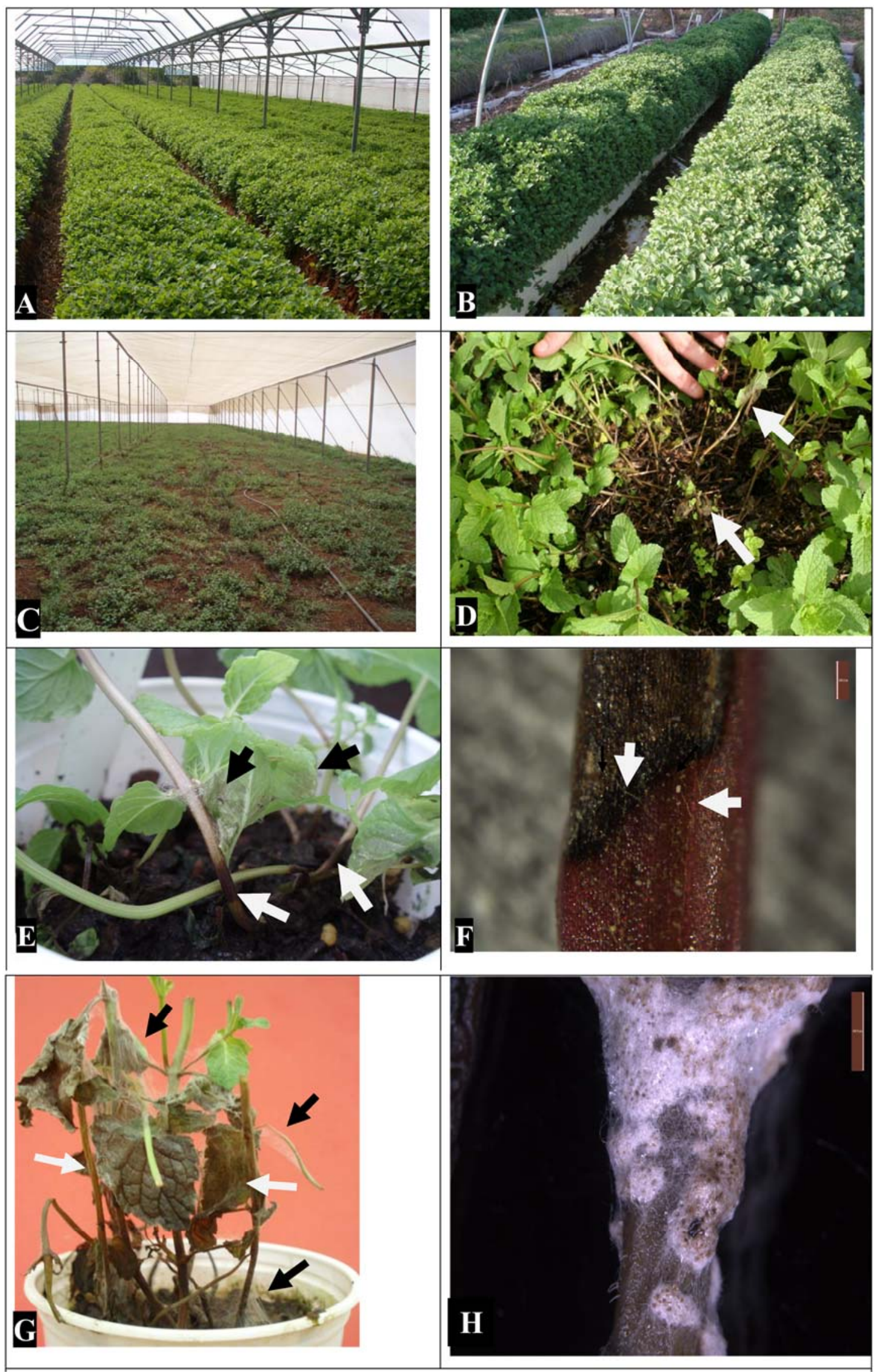

Fig. 1. Spanish mint cultivation and symptoms of Rhizoctonia web blight in Israel. A and B, Cultivation in a greenhouse and in polystyrene boxes filled with tuff (volcanic ash); C, patches of dead plants in a commercial shadehouse in the Jezreel Valley; D, close-up on a disease focus (blighted plant tissue is indicated by white arrows); E, brown lesions on stems (white arrow) and water-soaked leaf lesions with cobweb-like mycelia (black arrows) on an artificially inoculated mint plant; $\mathbf{F}$, microscopic close-up on mycelia extending from a stolon lesion (white arrow); G, blighted leaves and flaccid stems (white arrow) and cobweb-like mycelia (black arrows) on foliage of an artificially inoculated mint plant; $\mathbf{H}$, microscopic close-up of sclerotia and cobweb-like mycelia of isolate JV-1 on mint stem. 
the soil level or on the leaves. In late July 2010, symptomatic plants were collected from randomly selected foci and isolations from plant parts consistently yielded Rhizoctonia spp. Fulfillment of Koch's postulates using Spanish mint as a host indicated that the Rhizoctonia spp. was the causal agent of the web blight epidemic. The present study tested the hypothesis that strains of $R$. solani belonging to diverse AGs and possessing different ecological and pathological traits were the causal agents of the web blight epidemic recorded on mint in Israel. The goal of this study was to elucidate the etiology of the disease.

\section{Materials and Methods}

Fungal isolates. Two Rhizoctonia spp. isolates that were recovered directly from diseased Spanish mint plants were designated Jezreel Valley number 1 (JV-1) and Beit She'an Valley number 1 (BS-1) and used in this study. Each of the isolates represented a diseased mint plant that was collected from a single focus that was randomly selected. Isolate JV-1 originated from a diseased plant grown in a shadehouse and was collected in early August 2010 on a commercial Spanish mint farm located in the Jezreel Valley $\left(32^{\circ} 32^{\prime} 43.64^{\prime \prime} \mathrm{N}, 35^{\circ} 18^{\prime} 40.02^{\prime \prime}\right.$ E, elevation $+74 \mathrm{~m}$ ) (values adapted from Google Earth). Isolate BS-1 originated from a diseased plant grown in a tunnel on tuff and was collected in early October 2010 on a commercial farm located in the Beit She'an Valley $\left(32^{\circ} 26^{\prime} 55.09^{\prime \prime} \mathrm{N}, 35^{\circ} 28^{\prime} 23.32^{\prime \prime} \mathrm{E}\right.$, elevation $\left.-112 \mathrm{~m}\right)$. The isolates were recovered from surface-sterilized plants $(1 \%$ bleach for 5 min). The stems and leaves were cut into multiple segments and placed in 9-mm petri plates onto quarter-strength potato dextrose agar (QPDA, composed of $10 \mathrm{~g}$ of Difco PDA and $15 \mathrm{~g}$ of Bacto Agar dissolved in 1 liter of distilled water without antibiotics). The petri dishes were incubated in the dark at $27^{\circ} \mathrm{C}$. Three days later, an agar plug colonized by mycelium was transferred onto water agar (15 g of Bacto Agar in 1 liter of distilled water) in 9-mm petri plates and was incubated in the dark at $27^{\circ} \mathrm{C}$. Pure cultures were obtained by hyphal tipping. All tests in this study were conducted using the hyphal-tipped cultures.

Molecular characterization of isolates. Isolates were cultured in Luria-Bertani (LB) broth (20 g in 1 liter distilled water without antibiotics) for 7 days at $25^{\circ} \mathrm{C}$ in the dark without shaking. The mycelial mass was collected, washed with sterilized distilled water, and blotted dry on sterilized filter paper. Total DNA was extracted using the DNA Extraction GenElute Plant Genomic DNA Miniprep Kit (G2N350-1KT; Sigma-Aldrich), following the producer's protocol.

The rDNA-internal transcribed spacer (ITS) fragment (ribosomal ITS1, ITS2, and 5.8S) was amplified using the primers ITS4 (5'-TCCTCCGCTTATTGATATGC-3') and ITS5 (5'-GAAGTA AAAGTCGTAACAAGG-3') (31,37). The polymerase chain reaction (PCR) reaction for each sample included (in a total volume of $25 \mu \mathrm{l}) 12.5 \mu \mathrm{l}$ of $2 \times$ Reddy Mix PCR Master Mix (AB-0575; ABgene UK), $1 \mu \mathrm{M}$ each primer, $50 \mathrm{ng}$ of fungal DNA, and $8.5 \mu \mathrm{l}$ of purified water. The PCR program was as follows: one cycle of 2 min of denaturation at $94^{\circ} \mathrm{C}$ and 35 cycles of $30 \mathrm{~s}$ at $94^{\circ} \mathrm{C}, 1 \mathrm{~min}$ at $55^{\circ} \mathrm{C}$, and $1 \mathrm{~min}$ at $72^{\circ} \mathrm{C}$. The PCR terminated with one cycle of 20 min at $72^{\circ} \mathrm{C}$. The rDNA fragment (approximately $700 \mathrm{bp}$ ) was purified from the agarose gel with the aid of the High Pure PCR Product Purification Kit (catalog number 11732668001; Roche Applied Science).

The InsTAclone PCR Cloning Kit (K41213; Fermentas) was used to clone the DNA fragment into a $\mathrm{pTZ57R/T}$ plasmid vector with overnight ligation. The plasmid vector was inserted into $\mathrm{DH} \alpha 5$ Escherichia coli competent cells following the producer's protocol. The plasmid vector was extracted using the GeneElute HP Plasmid Miniprep Kit (Sigma, NA016-1KT). The integrated fragments were sequenced in a DNA sequencer (3130xl Genetic Analyzer, Hitachi) using BigDye Terminator v3.1 Cycle Sequencing Kit (AB Applied biosystems) premixed. Sequence processing was carried out using Chromas Lite (version 2.01; Technelysium Pty Ltd.).

The sequence of each isolate was subjected to BLAST (National Center for Biotechnology Information [NCBI]; www.ncbi.nlm.nih. gov) for species identification and then to AG identification using sequences of isolates obtained from previously published works $(24,31,34,35)$. The sequence of each isolate was aligned using ClustalW2 (EMBL-EBI; www.ebi.ac.uk/Tools/msa/clustalw2) to calculate the level of identity with previously published isolates. Phylogeny analysis and construction of the phylogenetic tree was conducted using the "a la carte" mode in the web-based service Phylogeny.fr (version 2; www.phylogeny.fr). The ShimodairaHasegawa-like approximate maximum likelihood ratio test in PhyML 3.0 was utilized for construction of the phylogenetic tree.

In vitro growth rate. Agar plugs $\left(1 \mathrm{~mm}^{2}\right)$ were transferred onto QPDA and each was placed in the center of a 9-cm-diameter petri plate. The plates were incubated at $10,15,20,25,27,30$, or $34^{\circ} \mathrm{C}$. The trials at each temperature were carried out twice, each time using three replicates per isolate. Colony diameter (radial growth) was recorded at multiple angles on a daily basis until the agar surface was covered by the fungal culture. The colony diameter was regressed on time using linear regression with the aid of the slope function in Microsoft Office Excel 2007. The fungal growth rate was calculated as the slope of the linear function. The fungal growth rate is presented as centimeters of hyphal growth per day.

Plant material. Spanish mint plants for experimental use were propagated from mature plants cultivated on the Newe Ya'ar farm. The upper $10 \mathrm{~cm}$ of the stems of disease-free plants were removed at random and were dissected into cuttings that included one or two nodes. The cuttings were transferred into 50-cell plug trays filled with Doron-3 growing media (Shaham Givat Ada Ltd.). Three cuttings were placed in each cell, and the flats were incubated in the greenhouse $\left(37^{\circ} \mathrm{C}\right.$ and $40 \% \mathrm{RH}$ to $26^{\circ} \mathrm{C}$ and $75 \%$ $\mathrm{RH}$, day and night, respectively) with approximately $12 \mathrm{~h}$ of daylight. The cuttings were irrigated for 5 min every $4 \mathrm{~h}$ using a computerized overhead sprinkler irrigation system. Two weeks later, the plantlets were transferred to experimental pots $(250$ $\mathrm{cm}^{3}$ ) in Doron-3 garden mix. The plantlets were fertilized twice a week with water-soluble 20:20:20 N:P:K fertilizer at a rate of $1 \mathrm{~g}$ per liter of water. Once the plants developed stolons or runners, they were considered to be mature and ready for artificial inoculation. All plants used in this study were approximately 1.5 months old.

Fungal inoculum. Wheat grains were used as carriers of fungal inoculum. The grains were washed in tap water and sterilized twice in the autoclave $\left(120^{\circ} \mathrm{C}\right.$ for $\left.60 \mathrm{~min}\right)$, with a $24-\mathrm{h}$ incubation period at $27^{\circ} \mathrm{C}$ in the dark between the two sterilizations. The isolates were subcultured on QPDA and incubated in the dark for 2 days at $27^{\circ} \mathrm{C}$. Three agar plugs from the edges of a growing colony were then transferred onto clean petri plates containing QPDA, and each plate was filled with sterilized wheat grains. The plates were sealed with Parafilm and incubated in the dark at $27^{\circ} \mathrm{C}$. A week later, the wheat grains were fully colonized with fungal mycelium and were ready for use. A single colonized wheat grain was considered a propagule for the purpose of inoculation.

Effect of temperature on disease. The trials were carried out in a growth chamber (Dahan Technologies). Three temperature regimes, representing the temperatures during the growing seasons in the different regions, were applied: 17 to 23,24 to 28 , and 30 to $35^{\circ} \mathrm{C}$. Plants were inoculated with isolate JV-1 or isolate BS-1 or remained uninoculated as controls. At each temperature, two trials were performed sequentially. All trials were carried out in a completely randomized design utilizing five replicates per treatment, except for the first trial at 24 to $28^{\circ} \mathrm{C}$, which had four replicates. Plant inoculation was carried out with each isolate separately. Five propagules were placed in the center of each pot among the mint branches, approximately $0.5 \mathrm{~cm}$ below soil level. Disease development was monitored daily and disease severity was recorded as the percentage of blighted or rotted foliage. The trials were terminated once disease severity in any of the inoculated treatments reached 90 to $95 \%$ on average.

The amount of disease was calculated as area under the disease progress curve (AUDPC), following the formula AUDPC $=\left\{\Sigma\left[\left(y_{i}\right.\right.\right.$ $\left.\left.\left.+y_{i+1}\right) / 2\right] \times\left(t_{i+1}-t_{i}\right)\right\}$, where $y_{i}$ and $y_{i+1}$ represent disease severities 
at $t_{i}$ and $t_{i+1}$, respectively (25). Disease rate was calculated by transformation of disease severity values with the formula $y^{*}=$ $\ln \{100 /(100-y)\}$ assuming a monomolecular epidemic, because plants in the growth chamber were each inoculated at a single time. Following transformation, $y^{*}$ was regressed on time with linear regression, and disease rate was calculated as the slope of the linear function. Yield was recorded at the end of each trial as the fresh weight (in grams) of nondiseased foliage, and yield reduction was calculated in relation to the noninoculated controls.

At the end of each trial, the infected plants were transferred to the greenhouse and exposed to $10^{\circ} \mathrm{C}$ at approximately 35 to $40 \%$ RH. These conditions restricted disease development but not plant growth. Plants were irrigated twice daily, and fertilized as above on a weekly basis. A month later, the number of plants that demonstrated foliar recovery and lack of fungal mycelia was recorded as a binary response, where $0=$ not recovered and $1=$ recovered. The frequency of recovered plants was evaluated per treatment.

Effect of RH on disease. Saturated salt solutions for humidity control were prepared following the previously published protocol by Winston (38) in sealed plastic boxes $(27 \mathrm{~cm}$ long by $20 \mathrm{~cm}$ wide by $8 \mathrm{~cm}$ deep). A plastic surface was situated inside the box and elevated approximately $3 \mathrm{~cm}$ above the salt solution. The $\mathrm{RH}$ conditions examined were $49,55,69,76,88$, and $100 \%$. Hobo data loggers (Onset Computer Corporation) were placed inside each box on top of the elevated surface, and the apparatus was placed in the growth chamber at $25 \pm 2{ }^{\circ} \mathrm{C}$ for 7 days in the dark until $\mathrm{RH}$ reached equilibrium. Polyacrylamide used for soil conditioning was prepared as a gel by mixing $10 \mathrm{~g}$ of the powder with 1 liter of tap water. The gel was placed in lids of 5-cm-diameter petri plates. Mint leaves (approximately $3.5 \mathrm{~cm}$ long by $2 \mathrm{~cm}$ wide) were removed from randomly selected plants (third pair of leaves below the apex) and a single leaf was placed on top of the gel in each of the petri plate lids. The gel prevented the leaves from drying out during the duration of the trial but did not affect the RH. A single wheat seed colonized by a 7-day-old culture with active mycelia of isolate JV-1 was placed at the edge of each detached leaf. Trials were carried out in a completely randomized design with a one-way structure (percent $\mathrm{RH}$ ) using four replicates per treatment. Disease severity was recorded daily as the percent of infected leaf area, and the amount of disease was calculated as AUDPC (25), as described above. The relationship of amount of disease (AUDPC) to RH was assessed by regression analysis. The regression model was selected following the least-squares procedure $(25,40)$.

Statistical analyses. All experiments were repeated in a completely randomized design with a one-way or two-way structure using isolates, temperature, or humidity as main fixed effects and three to five replicates per treatment. Analysis of variance (ANOVA) was carried out using the general linear models procedure (Proc GML) in SAS (version 9; SAS Institute) or with the Fit Models platform in JMP IN (version 5.1; SAS Institute, Inc.). The data were examined for normality using the Anderson-Darling test and for unequal variance using Levene's test. Where these assumptions were not fulfilled, the data were analyzed nonparametrically using the Kruskal-Wallis ANOVA by ranks (40). To explore differences between repeats of the same experiment, the data were initially analyzed as a split-plot design, with repeat as a blocking effect in the whole plot and temperature, isolate, or humidity as effects in the subplot. If the outcome indicated lack of difference among experiments, data from the repeats were analyzed jointly. Following ANOVA, means were separated with Fisher's protected least significant difference test. Differences between disease rates were explored with a two-tailed $t$ test using a single degree of freedom. Plant recovery was recorded as a binary response ( 1 or 0$)$ and was explored as a two-way contingency table with isolates and temperature as fixed effects using Fisher's exact test (40) in the Fit $\mathrm{Y}$ by $\mathrm{X}$ platform in JMP IN. Correlation analysis was carried out with Spearman's rank correlation procedure using the Multivariate Methods platform in JMP IN. Regression analyses were carried out using the Fit Curve platform in SigmaPlot (version 11; Systat Software, Inc.), and regression models were selected following the least-square method $(25,40)$. All inferences were made using a $5 \%$ significance level.

\section{Results}

Morphological and molecular characterization. Isolates JV-1 and BS-1 had hyphal branching at $90^{\circ}$ and white-hyaline mycelium which turned to buff on PDA 7 to 14 days following culturing. Isolate JV-1 produced abundant sclerotia on PDA immediately following culturing. The sclerotia were irregular in shape and dark brown in color, with diameters averaging 1 to $3 \mathrm{~mm}$. Isolate BS-1, on the other hand, produced a limited number of sclerotia of $1 \mathrm{~mm}$ in diameter on average, observable approximately 1.5 months after subculturing on PDA. The morphological features suggested that the two isolates were strains of $R$. solani.

The molecular analysis of the ITS region (ITS1, ITS2, and 5.8S) supported the morphological identification, indicating that both isolates were strains of $R$. solani. Alignment of the ITS region sequence to sequences of previously published $R$. solani isolates placed isolates JV-1 and BS-1 in AG 1-IB and AG 4-HG-I, respectively (Table 1). Isolate JV-1 had 87 to $98 \%$ homology to $R$. solani AG 1 isolates and $98 \%$ homology to those characterized to AG 1IB (Table 1). The phylogenetic analysis (Fig. 2) indicated that isolate JV-1 was closest to five $R$. solani isolates from Japan $(24,35)$, as follows: R102 from rice, TR22 from bentgrass, R52 from orchardgrass, SFBV-1 from sugar beet, and 001-7 from soil (GenBank accession numbers AB122138, AB122140, AB122137, $\mathrm{AB} 000038$, and AB000025, respectively; Fig. 2). Conversely, isolate BS-1 had 91 to $99 \%$ homology to $R$. solani AG 4 isolates and 96 to $99 \%$ homology to those characterized to AG4 HG-I (Table 1). The phylogenetic analysis indicated that isolate BS-1 was closest to isolates Str 43 from strawberry from Israel (31), and 78-23R-3 and AH-1 from spinach and peanut from Japan (24), respectively (GenBank accession numbers DQ102446, AB000007, and AB000012, respectively; Fig. 2).

The ITS sequences of isolates JV-1 and BS-1 were submitted to the NCBI and were assigned GenBank accession numbers JN254787 and JN254788, respectively.

In vitro and growth chamber trials. In vitro tests indicated an interaction between isolate and temperature $(P<0.0001)$. The optimal growth temperatures for isolates JV-1 and BS- 1 were 20 to 27 and 20 to $30^{\circ} \mathrm{C}$, respectively (Fig. 3). Isolate JV-1 had a faster $(P<0.0001)$ growth rate than isolate BS-1 at 20,25 , and $27^{\circ} \mathrm{C}$ but

Table 1. Sequence homology of rDNA (internal transcribed spacer [ITS]1, ITS2, and 5.8S) of isolates JV-1 and BS-1, recovered from Spanish mint (Mentha longifolia L.) in Israel in 2010, to previously reported Rhizoctonia solani isolates from different anastomosis groups $(\mathrm{AGs})^{\mathrm{a}}$

\begin{tabular}{lccc}
\hline & & \multicolumn{2}{c}{ Sequence homology $(\boldsymbol{\%})^{\mathbf{b}}$} \\
\cline { 3 - 4 } AG & $\boldsymbol{N}^{\mathbf{c}}$ & Isolate JV-1 & Isolate BS-1 \\
\hline AG-1 & 26 & $\mathbf{8 7 - 9 8}$ & $84-90$ \\
IA & 6 & $87-88$ & $\ldots$ \\
IB & $\mathbf{8}$ & $\mathbf{9 8}$ & $\ldots$ \\
IC & 4 & 91 & $\ldots$ \\
ID & 8 & $90-91$ & $\ldots$ \\
AG-4 & 25 & $86-88$ & $\mathbf{9 1 - 9 9}$ \\
HG-I & 12 & $\ldots$ & $\mathbf{9 6 - 9 9}$ \\
HG-II & 9 & $\ldots$ & $95-96$ \\
HG-III & 3 & $\ldots$ & $91-93$ \\
AGs-2, 3, and 5-9 & $1-9$ & $82-91$ & $80-96$ \\
Outgroup & & 59 & 56 \\
\hline
\end{tabular}

${ }^{\text {a }}$ Numbers in bold indicate the highest sequence homology.

b Sequence homology was evaluated using ClustalW2 multiple sequence alignment tool (www.ebi.ac.uk). Isolates JV-1 and BS-1 were aligned to a total of 74 ITS-5.8S rDNA sequences of isolates/GenBank accessions previously published $(24,31,34,35)$ and available via GenBank (www. ncbi.nlm.nih.gov).

${ }^{c}$ Number of isolates/GenBank accessions evaluated for homology.

${ }^{\mathrm{d}}$ Fusarium solani f. sp. pisi. 
not at 10,15 , or $30^{\circ} \mathrm{C}$, where the growth of the two isolates was similar $(P>0.05)$. At $34^{\circ} \mathrm{C}$, isolate BS-1 demonstrated faster $(P=$ 0.015) growth than isolate JV-1.

In the growth-chamber trials, fungal hyphae were easily observed on both foliage and soil (Fig. 1E). Diseased leaf tissue initially became water-soaked (Fig. 1E) and then necrotic (Fig. 1G).
Necrosis was accompanied by fungal hyphae developing on the stems and leaves. As disease progressed, the plant became engulfed by the fungal mycelium, which appeared as a cob-like web (Fig. $1 \mathrm{G})$. Although covered by fungal mycelium, the necrotic and rotted stems did not collapse but remained erect, and the rotted leaves remained attached to the stems (Fig.1G).

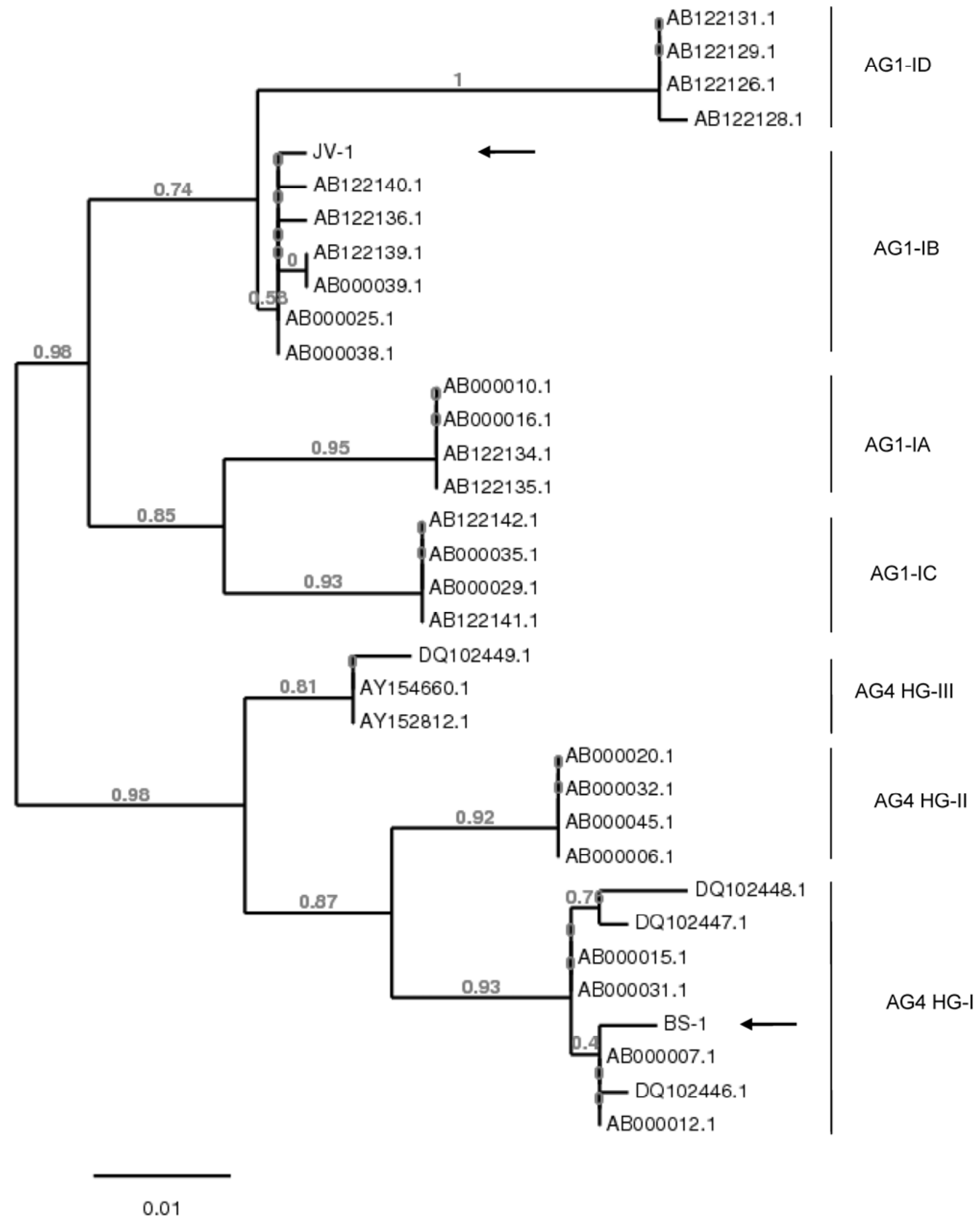

Fig. 2. Limited phylogenetic tree illustrating the relationship of Rhizoctonia web blight isolates JV-1 and BS-1 from mint in Israel (black arrows) to other $R$. solani isolates previously assigned $(24,31,34,35)$ to anastomosis groups (AGs) 1 and 4 , respectively, based on internal transcribed spacer-5.8S rDNA region sequences. The phylogenetic tree was constructed with the Phylogeny.fr program version 2 (www.phylogeny.fr). 
At 17 to $23^{\circ} \mathrm{C}$, fungal signs were observed $24 \mathrm{~h}$ post inoculation, and symptoms of disease were noted 2 days post inoculation (Fig. 4A). Disease severity at 17 to $23^{\circ} \mathrm{C}$ reached a maximum of 96 and $42 \%$ for isolates JV-1 and BS-1, respectively, 11 days post inoculation. At 24 to $28^{\circ} \mathrm{C}$, fungal signs were observable $24 \mathrm{~h}$ post inoculation and symptoms of disease were noted $24 \mathrm{~h}$ later (Fig. 4B). Disease severity at 24 to $28^{\circ} \mathrm{C}$ reached a maximum of 99 and $94 \%$ for isolates JV-1 and BS-1, respectively, 7 days post inoculation (Fig. 4B). At 30 to $35^{\circ} \mathrm{C}$, fungal signs were also observable $24 \mathrm{~h}$ post inoculation; however, disease symptoms were first noted 3 days post inoculation, and disease severity reached a maximum of 65 and $90 \%$ for isolates JV-1 and BS-1, respectively, 14 days post inoculation (Fig. 4C). Consistent with the in vitro development on PDA, isolate JV-1 developed sclerotia on stems (Fig. 1H) immediately following plant death, whereas isolate BS-1 had sclerotia developing on dead plant stems approximately 1 to 2 months following plant death.

The amount of Rhizoctonia web blight caused by isolates JV-1 and BS-1, based on calculation of AUDPC, was significantly affected by temperature $(P<0.0001$; Fig. 4). Isolates JV-1 and BS-1 caused similar amounts of disease at 24 to $28^{\circ} \mathrm{C}(P=0.8362$; Fig. 4B). However, at 17 to $23^{\circ} \mathrm{C}$, isolate JV-1 caused more disease than isolate BS-1 whereas, at 30 to $35^{\circ} \mathrm{C}$, isolate BS-1 was the more aggressive $(P=0.0007$ and $P<0.0001$; Fig. 4A and $\mathrm{C}$, respectively).

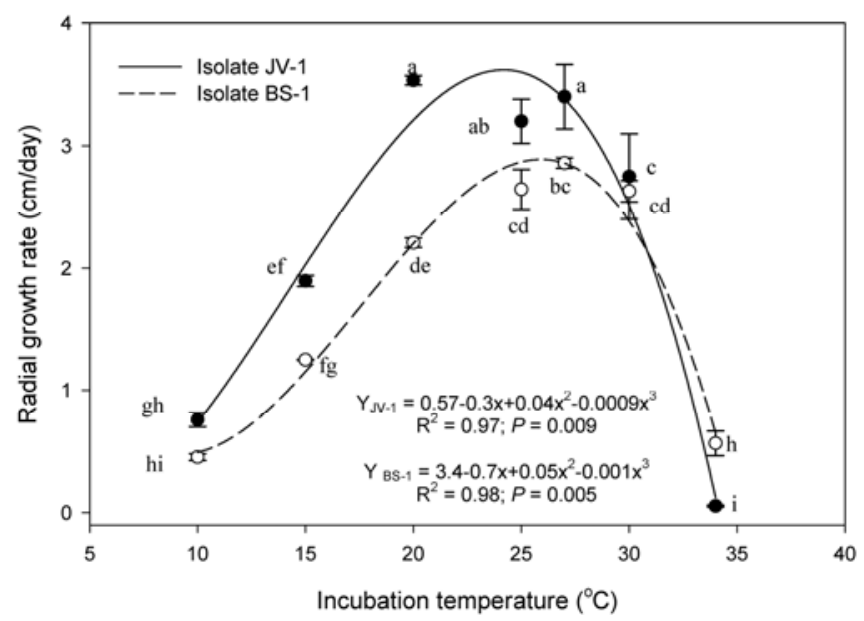

Fig. 3. In vitro growth rate of isolates JV-1 and BS-1 at 10, 15, 20, 25, 27, 30, and $34^{\circ} \mathrm{C}$. Data points are mean \pm standard error. Different lowercase letters represent significant $(P<0.05)$ differences among the growth rates. The cubic function demonstrated the best fit $(P<0.05)$ following the least square method $(40)$.
The rate of development of Rhizoctonia web blight was significantly affected by temperature $(P<0.0001$; Fig. 5). Among the three temperature regimes tested, both isolates had the highest $(P<$ $0.0001)$ disease rates at 24 to $28^{\circ} \mathrm{C}(P<0.0001$; Fig. 5A and $\mathrm{B})$. The rate of disease caused by isolate JV-1 was higher at 17 to 23 than at 30 to $35^{\circ} \mathrm{C}(P<0.0001)$ but not higher than at 24 to $28^{\circ} \mathrm{C}$ $(P>0.05$; Fig. 5A). In a similar manner, the rate of disease caused by isolate BS-1 was higher at 30 to 35 than at 17 to $23^{\circ} \mathrm{C}(P<$ 0.0001 ) but it was not higher than at 24 to $28^{\circ} \mathrm{C}$ (Fig. 5B).

Yield of inoculated plants was reduced at all temperature regimes tested by both isolates compared with the noninoculated plants (Fig. 6). The total reduction of yield across all temperatures ranged between 46 and $100 \%$. Isolates' ability to cause yield reduction was affected by temperature $(P=0.0003)$. Isolate $\mathrm{JV}-1$ caused more yield reduction at 17 to 23 and 24 to 28 than at 30 to $35^{\circ} \mathrm{C}$ ( $P<0.0001$, respectively). On the other hand, isolate BS-1 caused more yield reduction at 24 to 28 than at 17 to 23 or 30 to $35^{\circ} \mathrm{C}(P=0.005$ and 0.0037 , respectively). Comparing the two isolates, JV-1 reduced yield more than BS-1 at 17 to $23^{\circ} \mathrm{C}(P=$ $0.0026)$. The isolates reduced yield similarly at 24 to 28 and 30 to $35^{\circ} \mathrm{C}(P=0.889$ and 0.191 , respectively; Fig. 6). Yield reduction correlated significantly to disease rate $(P<0.0001)$ with Spearman's rank coefficient of 0.8278 .

Rhizoctonia web blight affected plants' recovery and foliar regrowth following the transfer of plants from the trial temperature to a disease-restricting temperature. The frequency of plant recovery differed among the temperatures $(P<0.0001)$ but not between the isolates $(P=0.101)$. At 24 to $28^{\circ} \mathrm{C}, 77.5 \%$ fewer $(P<0.0001)$ plants recovered from web blight than at 17 to 23 or 30 to $35^{\circ} \mathrm{C}$, where a $90 \%$ recovery was recorded.

The development of disease on detached leaves in the humidity chamber at different RH levels is summarized in Figure 7. At $24 \mathrm{~h}$ post inoculation, web blight was recorded at 15.6, 5.7, and $2 \%$ severity at 100,88 , and $76 \%$ RH treatments, respectively. Disease reached $100,99.8$, and $95 \%$ severity at 100,88 , and $76 \%$ RH at 48 , 72, and $72 \mathrm{~h}$ post inoculation, respectively (Fig. 7A). Interaction between the amount of web blight (AUDPC) and trial was not recorded $(P=0.117)$ and the data of both trials were analyzed jointly. AUDPC differed significantly among the RH treatments $(P<$ $0.05)$. The highest AUDPC was recorded at $100 \% \mathrm{RH}$ followed by 88, 76, 69, 55, and 49\% (Fig. 7B). The relationship between the amount of disease (AUDPC) on the detached leaves and relative humidity was adequately explained by a quadratic fit $(P<0.0015$, $R^{2}=0.978$; Fig. 7B).

\section{Discussion}

The web blight epidemic on mint in Israel was the outcome of infection by $R$. solani. Rhizoctonia web blight is documented in the literature as a destructive, yield-reducing disease on several com-
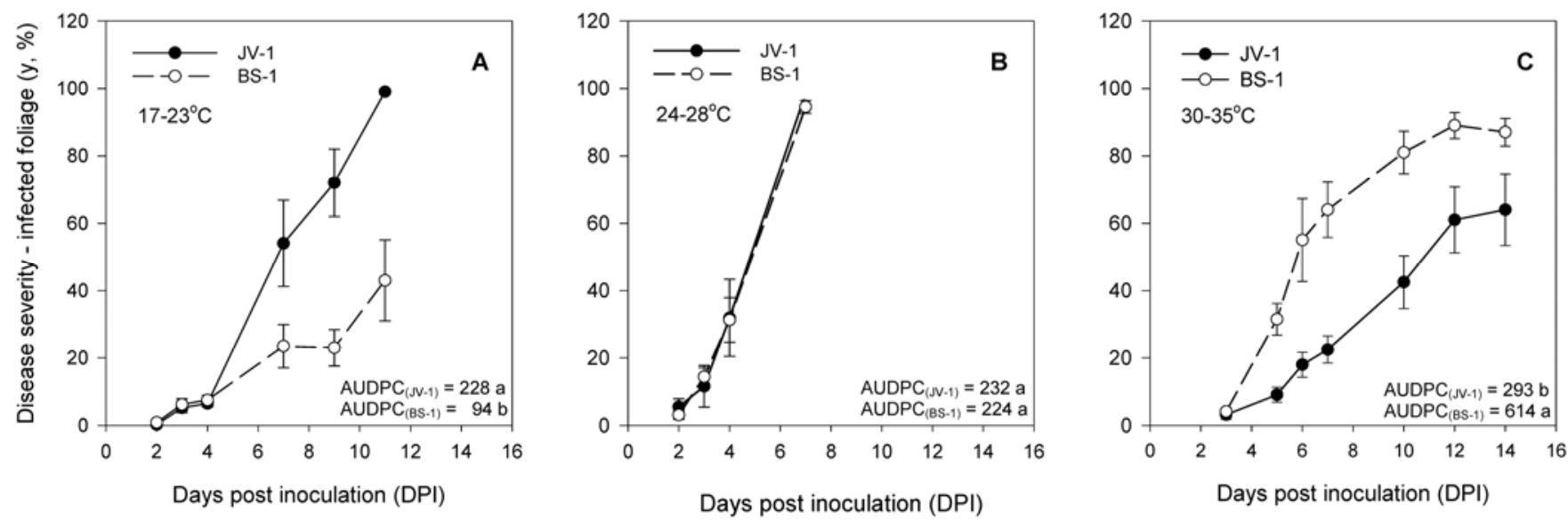

Fig. 4. Disease progress curves of Rhizoctonia web blight on mint plants grown in a growth chamber and inoculated with isolates JV-1 and BS-1 at three different temperature regimes. Data points are mean \pm standard error. Different lowercase letters following area under the disease progress curve (AUDPC) values indicate significant $(P<0.05)$ differences between the isolates. 

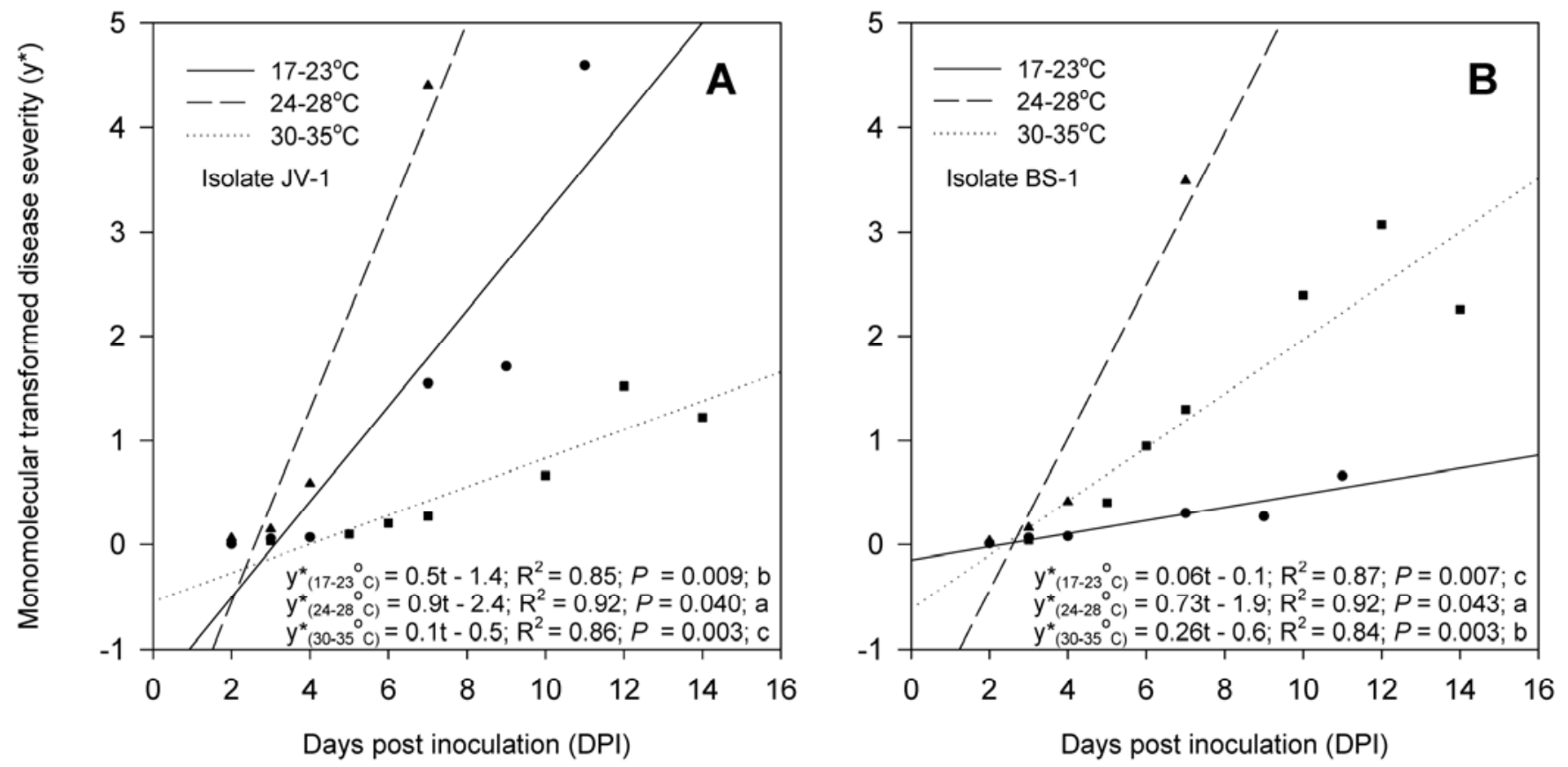

Fig. 5. Rate of Rhizoctonia web blight development on mint plants grown in the growth chamber and inoculated with isolates A, JV-1 and B, BS-1 at three different temperature regimes. Disease severity values $(y, \%)$ were linearized using the monomolecular model transformation following the formula $y^{*}=\ln [100 /(100-y)(25)$. The linear function of each regression line is followed by the coefficient of determination $\left(R^{2}\right)$ and significance level $(P$ value $)$ of the regression. Lowercase letters represent statistical differences among the slopes of the regression lines (rates of disease).

mercially important plant species, such as common bean (12), soy bean (39), rosemary (7), verbana (17), and container-grown azalea (8). The disease also was reported on mint in Florida (3), India (22), and China (11); however, these reports presented limited information about the extent of damage or etiology on mint. To the best of our knowledge, this is the first report of $R$. solani causing web blight on any crop in Israel, and specifically on mint, and the first comprehensive description of the disease etiology on this particular crop.

Isolates JV-1 and BS-1, which were isolated from randomly selected web-blight-symptomatic plants in the Jezreel and BeitShe'an valleys, were assigned to AGs 1-IB and 4-GH-I, respectively. AGs 1 and 4 have previously been associated with Rhizoctonia web blight $(5,13,14,16,28)$, as well as AGs 2 (16) and 3 (5). Ichielevich-Auster (19) reported the presence, in Israeli soils, of $R$. solani isolates assigned to the abovementioned AGs, as well as isolates belonging to AGs 5, 6, and 7 and binucleate isolates, and demonstrated their pathogenicity on various crops. Also, Sharon et al. (31) demonstrated the occurrence of AG 4 isolates as causal agents of root rot of strawberry in Israel. Therefore, although Rhizoctonia web blight was not previously reported in Israel and its origin is unclear, sources of inoculum are available, and it is possible that $R$. solani strains belonging to additional AGs are involved with this disease in Israel.

Web blight in Israel was observed at the Jazreel and Beit Shean valleys most frequently during the summer (June through September) but also during the winter (November through March), though to a lesser extent. Temperatures at the Jezreel Valley range from 12 to $28^{\circ} \mathrm{C}$ and at the Beit She'an Valley from 16 to $37^{\circ} \mathrm{C}$ (Israeli Meteorological Service; www.ims.gov.il). The pathogenicity of isolates JV-1 and BS-1 corresponded with this wide temperature range and their aggressiveness significantly interacted with temperature. At the cooler temperature regime $\left(17\right.$ to $\left.23^{\circ} \mathrm{C}\right)$, isolate $\mathrm{JV}$ 1 caused more disease than isolate BS-1. However, at the warmer temperature regime $\left(30\right.$ to $\left.35^{\circ} \mathrm{C}\right)$, isolate BS-1 caused more disease than isolate JV-1. Interestingly, isolate JV-1 originated from the cooler Jezreel Valley, whereas isolate BS-1 originated from the warmer Beit She'an Valley; an observation that may suggest an ecological adaptation $(15,23)$. Nevertheless, both isolates had optimal in vitro growth and highest disease rates between 24 and $28^{\circ} \mathrm{C}$.

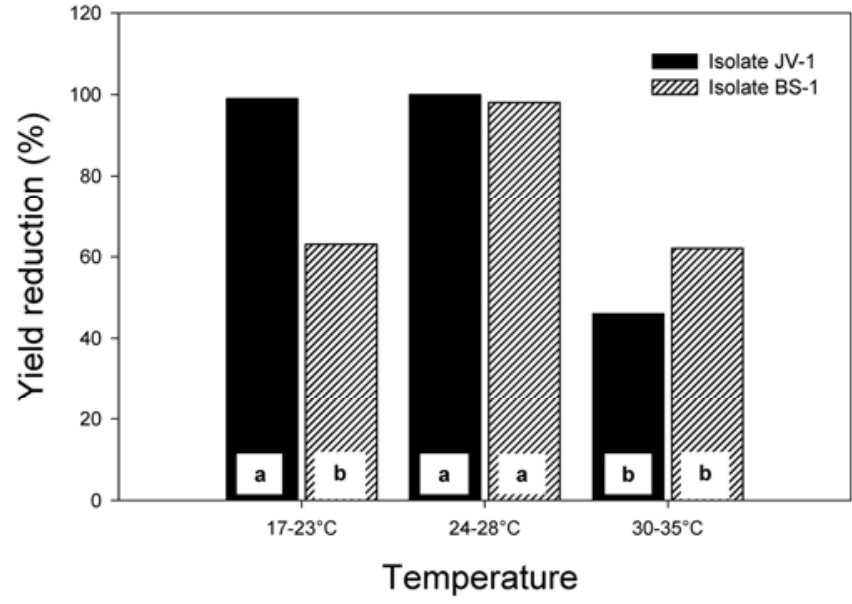

Fig. 6. Reduction of foliage fresh weight of mint plants due to infection by Rhizoctonia web blight isolates JV-1 and BS-1 at three different temperature regimes. Different lowercase letters indicate significant $(P<0.05)$ differences in yield reduction.

At this temperature range, the two isolates inflicted the most severe disease, as indicated by the lowest plant recovery frequency of $12.5 \%$ compared with $90 \%$ recovery at 17 to 23 or 30 to $35^{\circ} \mathrm{C}$. The low recovery frequency indicates infection and eradication of the underground stolons or runners, which are the main structures of vegetative reproduction in mint. The low recovery frequency is consistent with the brown patches of dead foliage and barren spots observed in the Jezreel Valley (Fig. 1C).

The effect of RH on web blight was studied utilizing a detachedleaf assay. The technique was adapted from previous studies $(18,27,38)$ and proved useful, demonstrating an ability to distinguish disease development among different RH treatments. Web blight developed at a wide range of $\mathrm{RH}$ and demonstrated a polynomial relationship to $\mathrm{RH}$ with a quadratic fit, indicating the lack of $\mathrm{RH}$ threshold. Most disease occurred at $100 \% \mathrm{RH}$, and decreased significantly by 1.3-, 1.9-, 3.0-, 4.5-, and 10.5-fold with the reduction of RH from $100 \%$ to $88,76,69,55$, or $49 \%$, respectively. 

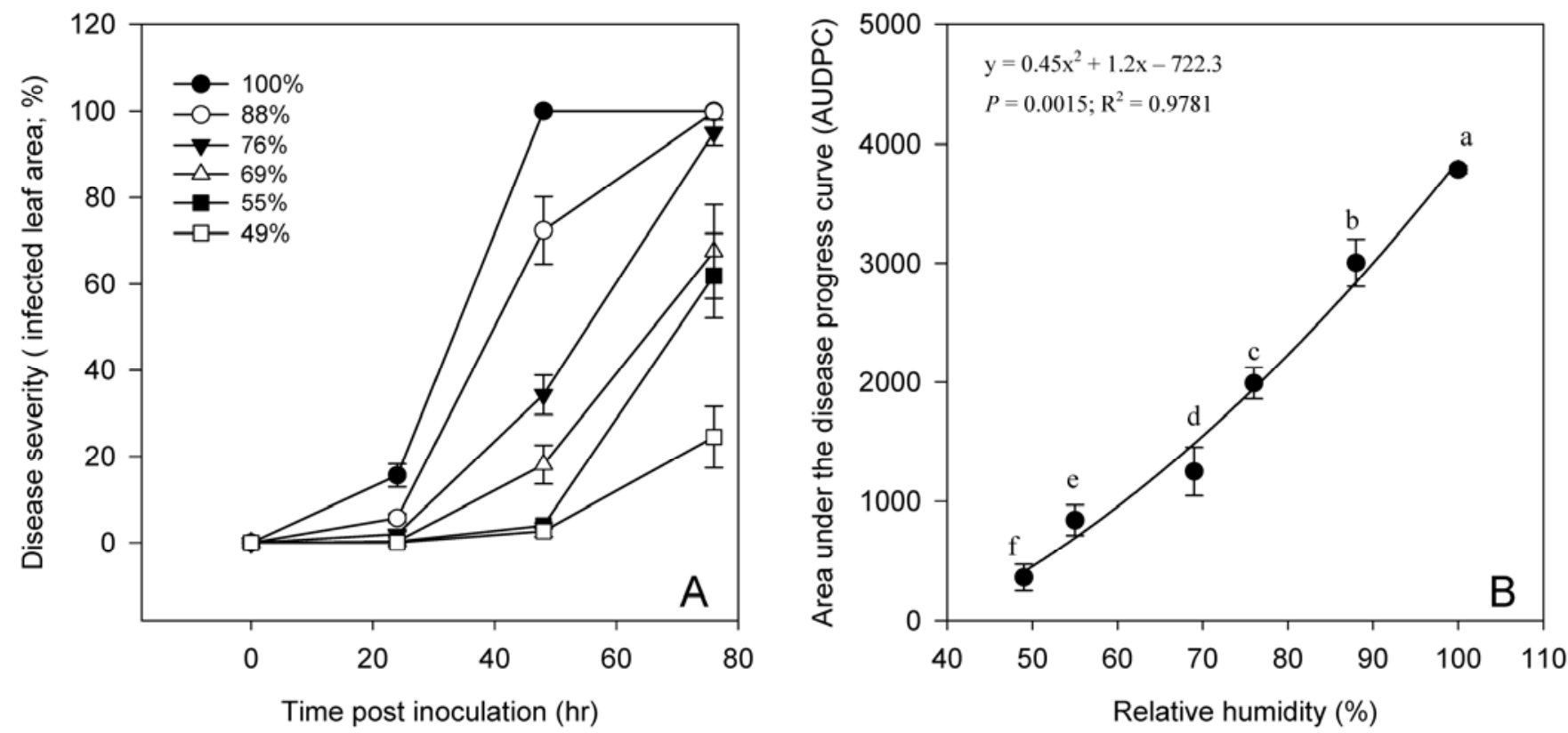

Fig. 7. A, Rhizoctonia web blight progress curve at five different relative humidities (RHs) and $\mathbf{B}$, the corresponding area under the disease progress curve (AUDPC) and its relationship to $\mathrm{RH}$. Different lowercase letters indicate significant $(P<0.05)$ differences in AUDPC values between the RH treatments. The quadratic trend adequately described the relationship between the AUDPC and percent $\mathrm{RH}\left(P=0.0015, R^{2}=0.978\right)$.

This indicated the potential for web blight reduction by manipulation of RH in the growing environment. Achieving disease control through reduction of relative humidity would be challenging but not impossible. Replacing sprinkler or aboveground drip irrigation with buried drip irrigation could reduce $\mathrm{RH}$ at the soil level and prevent free water on the ground or foliage. Air movement could be increased in tunnels using fans, and plant density could be reduced by spacing plants out, or by mechanical flailing.

Currently, Rizolex 500SC (tolclofos-methyl at $500 \mathrm{~g} / \mathrm{liter}$; Sumitomo Chemical Company Ltd.) is under examination as an emergency means for web blight control, and the preliminary results indicate reduction of disease (data not shown). However, fresh spice herbs are crops where fungicide application is highly restricted. Hence, Rizolex can only be a short-term solution, and other long-term solutions such as resistant varieties and cultural practices should be examined.

The present study used only two $R$. solani isolates from diverse geographical regions in Israel to learn about the newly discovered web blight on Spanish mint. To fully understand web blight etiology and epidemiology on Spanish mint in Israel, it would be necessary to assay a larger number of $R$. solani isolates from diseased Spanish mint plants. This could confirm the difference in optimum temperature and disease found between the two isolates used. With this in mind, the present study is a first step toward enhancing web blight control on Spanish mint in Israel.

\section{Acknowledgments}

We thank S. Gal, Department of Entomology, ARO, Newe Ya'ar, Israel, for her technical assistance; D. Shteinberg, Department of Plant Pathology and Weeds Science, ARO, Beit Dagan, Israel, for his assistance in calculating disease rates; T. Schubert, FDACS, Gainesville, FL, for providing knowledge regarding Rhizoctonia web blight in Florida; and L. Porter of the United States Department of Agriculture-Agricultural Research Service in Prosser, WA, for his critical review of this work.

\section{Literature Cited}

1. Adams, G. C., Jr. 1988. Thanatephorus cucumeris (Rhizoctonia solani): A species complex of wide host range. Adv. Plant Pathol. 6:535-552.

2. Aflatuni, A., Uusitalo, J., Ek, S., and Hohtola, A. 2005. Variation in the amount of yield and in the extract composition between conventionally produced and micropropagated peppermint and spearmint. J. Essen. Oil Res. 17:66-70.

3. Alfieri, S. A., Jr., Langdon, K. R., Whelburg, C., and Kimbrough, J. W. 1984. Index of plant diseases in Florida. Fla. Dep. Agric. Consumer Serv. Div. Plant Ind. Bull. No. 11.
4. Bacharis, C., Gouziotis, A., Kalogeropoulou, P., Koutita, O., Tzavella-Klonari, K., and Karaoglanidis, G. S. 2010. Characterization of Rhizoctonia spp. isolates associated with damping-off disease in cotton and tobacco seedlings in Greece. Plant Dis. 94:1314-1322.

5. Bartz, F. E., Cubeta, M. A., Toda, T., Naito, S., and Ivors, K. L. 2010. An in planta method for assessing the role of basidiospores in Rhizoctonia foliar disease of tomato. Plant Dis. 94:515-520.

6. Carling, D. E., Kuninaga, S., and Brainard, K. A. 2002. Hyphal anastomosis reactions, rDNA-internal transcribed spacer sequences, and virulence levels among subsets of Rhizoctonia solani anastomosis group-2 (AG-2) and AGBI. Phytopathology 92:43-50.

7. Conway, K. E., Maness, N. E., and Motes, J. E. 1997. Integration of biological and chemical controls for Rhizoctonia aerial blight and root rot of rosemary. Plant Dis. 81:795-798.

8. Copes, W. E., and Scherm, H. 2010. Rhizoctonia web blight development on container-grown azalea in relation to time and environmental factors. Plant Dis. 94:891-897.

9. Cubeta, M. A., and Vilgalys, R. 1997. Population biology of the Rhizoctonia solani complex. Phytopathology 87:480-484.

10. Dorrance, A. E., Kleinhenz, M. D., McClure, S. A., and Tuttle, N. T. 2003. Temperature, moisture, and seed treatment effects on Rhizoctonia solani root rot of soybean. Plant Dis. 87:533-538.

11. Duan, C.F., Yang, G., Ni, Z., Liu, G., and Wu, H. 2008. Occurance of foliar rot of Chinese cabbage, mint and lettuce caused by Rhizoctonia solani AG-1 IB in China. J. Yunnan Agric. Univ. 3.

12. Galindo, J. J., Abawi, G. S., Thurston, H. D., and Galvez, G. 1983. Source of inoculum and development of bean web blight in Costa Rica. Plant Dis. 67:1016-1021.

13. Garibaldi, A., Gilardi, G., Bertetti, D., and Gullino, M. L. 2010. First report of leaf blight on woodland sage caused by Rhizoctonia solani AG 1 in Italy. Plant Dis. 94:1071.

14. Garibaldi, A., Minuto, A., Bertetti, D., Nicoletti, R., and Gullino, M. L. 2003. First report of web blight on yellow-sage (Lantana camara) caused by Rhizoctonia solani in Europe. Plant Dis. 87:875.

15. Gill, J. S., Sivasithamparam, K., and Smettem, K. R. J. 2001. Effect of soil moisture at different temperatures on Rhizoctonia root rot of wheat seedlings. Plant Soil 231:91-96.

16. Godoy-Lutz, G., Steadman, J. R., Higgins, B., and Powers, K. 2003. Genetic variation among isolates of the web blight pathogen of common bean based on PCR-RFLP of the ITS-rDNA region. Plant Dis. 87:766771 .

17. Holcomb, G. H. 2000. First report of web blight on verbena caused by Rhizoctonia solani. Plant Dis. 84:492.

18. Hong, T. D., Edgington, S., Ellis, R. H., Aquino de Muro, M., and Moore, D. 2005. Saturated salt solutions for humidity control and the survival of dry powder and oil formulations of Beauveria bassiana conidia. J. Invertebr. Pathol. 89:136-143.

19. Ichielevich-Auster, M., Sneh, B., Koltin, Y., and Barabash, I. Pathogenicity, host specificity and anastomosis groups of Rhizoctonia spp. isolated from soils in Israel. Phytoparasitica 13:103-112. 
20. Johnson, D. A., and Cummings, T. F. 2000. Evaluation of mint mutants, hybrids, and fertile clones for resistance to Verticillium dahliae. Plant Dis. $84: 235-238$.

21. Johnson, D. A., and Santo, G. S. 2001. Development of wilt in mint in response to infection by two pathotypes of Verticillium dahliae and coinfection by Pratylenchus penetrans. Plant Dis. 85:1189-1192.

22. Kalra, A., Singh, H. B., Pandey, R., Samad, A., Patra, N. K., and Kumar, S. 2005. Diseases in mint: causal organisms, distribution, and control measures. J. Herbs Spices Med. Plants 11:71- 91.

23. Kumar, S., Sivasithamparam, K., Gill, J. S., and Sweetingham, M. W. 1999. Temperature and water potential effects on growth and pathogenicity of Rhizoctonia solani AG-11 to lupin. Can. J. Microbiol. 45:389-395.

24. Kuninaga, S., Natsuaki, T., Takeuchi, T., and Yokosawa, R. 1997. Sequence variation of the rDNA ITS regions within and between anastomosis groups in Rhizoctonia solani. Curr. Genet. 32:237-243.

25. Madden, L. V., Hughes, G., and Van den Busch, F. 2007. The Study of Plant Disease Epidemics, American Phytopathological Society, St. Paul, MN.

26. Morton, J. F. 1976. Herbs and Spices. A Golden Guide. Golden Press, NY. Western Publishing Company, Inc., Racine, WI.

27. O'Brien, F. E. M. 1948. The control of humidity by saturated salt solutions. J. Sci. Instrum. 25:73.

28. Ogoshi, A. 1987. Ecology and pathogenicity of anastomosis and intraspecific groups Rhizoctonia solani Kühn. Annu. Rev. Phytopathol. 25:125-143.

29. Ogoshi, A. 1996. Introduction-The genus Rhizoctonia. Pages 1-9 in: Rhizoctonia Species: Taxonomy, Molecular Biology, Ecology, Pathology and Disease Control. B. Sneh, S. Jabaji-Hare, S. Neate, and G. Dijst, eds. Kluwer Academic Publishers, Dordrecht, The Netherlands.

30. Ruttle, M. L. 1974. Some common mints and their hybrids. Page 92 in: Herbs for Use and For Delight. An Anthology from The Herbalist. A
Publication of the Herb Society of America. D. J. Foley, ed. Dover Publication, Inc., New York.

31. Sharon, M., Freeman, S., Kuninage, S., and Sneh, B. 2007. Genetic diversity, anastomosis groups and virulence of Rhizoctonia spp. from strawberry. Eur. J. Plant Pathol. 117:247-265.

32. Sneh, B., Burpee, L., and Ogoshi, A. 1991. Identification of Rhizoctonia Species. American Phytopathological Society, St. Paul, MN.

33. Sneh, B., Jabaji-Hare, S., Neate, S., and Dijst, G., eds. 1996. Rhizoctonia Species: Taxonomy, Molecular Biology, Ecology, Pathology and Disease Control. Kluwer Academic Publishers, Dordrecht, The Netherlands.

34. Suga, H., Hasegawa, T., Mitsui, H., Kageyama, K., and Hyakumachi, M. 2000. Phylogenetic analysis of the phytopathogenic fungus Fusarium solani based on the rDNA-ITS region. Mycol. Res. 104:1175-1183.

35. Toda, T., Mghalu, M. J., Priyatomojo, A., and Hyakumachi, M. 2004. Comparison of sequences for the internal transcribed spacer region in Rhizoctonia solani AG1-ID and other subgroups of AG1. J. Gen. Plant Pathol. 70:270-272.

36. Tucker, A. O., and Naczi, R. F. C. 2007. Mentha: An overview of its classification and relationships. In: Mint: The Genus Mentha. B. M. Lawrence, ed. CRC Press, Taylor and Francis Group, Boca Raton, FL.

37. White, T. J., Bruns, T., Lee, S., and Taylor, J. 1990. Amplification and direct sequencing of fungal ribosomal RNA genes for phylogenetics. Pages 315 322 in: PCR Protocols, A Guide to Methods and Applications. M. A. Innis, D. H. Gelfand, and J. J. Sninsky, eds. Academic Press, San Diego, CA.

38. Winston, P. W. 1960. Saturated solutions for the control of humidity in biological research. Ecology 41:232-237.

39. Yang, X. B., Berggren, G. T., and Snow, J. P. 1990. Types of Rhizoctonia foliar blight on soy bean in Louisiana. Plant Dis. 74:501-504.

40. Zar, H. J. 1999. Biostatistical Analysis, 4th ed. Pearson Education, Inc. 